\title{
SEPARATION OF NORMAL OCTANE FROM PETROLEUM BY DISTILLATION AND CRYSTALLIZATION ${ }^{1}$
}

\author{
By R. T. Leslie and Sy!vester T. Schicktanz
}

\section{ABSTRACT}

An interlocking process of distillation and crystallization is outlined for the separation of $n$-octane from petroleum. The laboratory stills used and various forms of laboratory apparatus suitable for crystallization at low temperatures are described. The boiling point, freezing point, refractive index, and molecular weight of the product are given and are compared with the properties of a carefully purified sample of synthetic $n$-octane. It is estimated that the $n$-octane content of the oil under consideration is not less than 1.0 per cent.

\section{CONTENTS}

I. Introduction $\ldots \ldots \ldots$

1. Preliminary distillation 378

2. Apparatus for crystallization 378

3. Method of fractional crystallization .

4. Method of interlocking crystallization and distillation

III. Properties of the product

IV. Estimate of the $n$-octane content of the crude petroleum

\section{INTRODUCTION}

A complex mixture, such as petroleum, in which many compounds with nearly the same boiling point probably exist and in which constant boiling mixtures may be formed, can not be separated into its constituent hydrocarbons by fractional distillation alone. ${ }^{2}{ }^{3}$ It has been previously pointed out that fractional crystallization might offer a method of breaking up such constant boiling mixtures, ${ }^{4} 56$ but the method has not been very extensively employed in cases in which temperatures much below those attainable with ice mixtures are required. The advent of "dry ice" (solid $\mathrm{CO}_{2}$ ) as an article of commerce has extended the usefulness of the method to much lower temperatures.

In addition to the low temperatures necessary, there are other difficulties associated with the general application of fractional crystallization to the problem of separating hydrocarbons. Many of these systems have a tendency to supercool and become highly viscous, especially if their freezing points are very low. Frequently the hydrocarbons cool to vitreous solids even when in a comparatively

1 This paper describes some of the results obtained in an investigation on The Separation, Identification, and Determination of the Chemical Constituents of Commercial Petroleum Fractions, listed as project No. 6 of the American Petroleum Institute Research. Financial assistance in this work has been recoived from a research fund of the American Petroleum Institute donated by John D. Rockefeller. This fund is being administered by the institute with the cooperation of the Central Petroleum Committee of the National Research Council.

2 Brooks, Nonbenzenoid IIydrocarbons, Chemical Catalogue Co., pp. 18, 24; 1922.

3 Young, Fractional Distillation, Macmillan Co., p. 255; 1903

4 Young, Fractional Distillation, Miacmillan Co., p. 142; 1903.

5 Washburn, Bruun, and Hicks, B. S. Jour. Of Researcli, 2, p. 467; 1929.

- Sunier and Rosenblum, Ind. Eng. Chem., Ansl. pd., 2, p. 109; 1930. 
pure state. ${ }^{7}$ The data in the literature on the freezing points of these hydrocarbons are somewhat incomplete apparently for this reason.

In a complex mixture, such as petroleum, it is impossible to predict what may occur on freezing. It is probable, however, that the hydrocarbons will crystallize as solid solutions or eutectic mixtures rather than as molecular compounds if the viscosity does not interfere with normal freezing. ${ }^{8}$ If a solid solution results, separation by fractional crystallization will usually be slow. If eutectic freezing occurs in a mixture which is richer in one constituent than the eutectic composition, a single substance may separate first and can then be removed in a pure state except for adhering mother liquid. To be amenable to fractionation by crystallization, therefore, a system of hydrocarbons should not have the eutectic composition.

\section{METHOD AND APPARATUS}

\section{PRELIMINARY DISTILLATION}

The material employed in this investigation was a 200-liter fraction of petroleum boiling roughly between $100^{\circ}$ and $130^{\circ} \mathrm{C}$. which had been obtained by the distillation in a semicommercial still of 2,300 liters (600 gallons) of crude petroleum from well No. 6 of the South Ponca field of Oklahoma, ${ }^{9}$ and which was given a further distillation through a metal bubbling-cap column having 20 plates. $^{10}$ The $2^{\circ}$ to $3^{\circ}$ cuts resulting from these distillations were then distilled in $1^{\circ}$ cuts in a battery of glass column stills. Each column consisted of 10 to 12 units of the type shown in Figure 1, with a head of the design shown in the same figure, by means of which very high reflux ratios could be obtained. These distillations were continued until considerable separation of the constituents began to occur, as indicated by the distribution of the volumes over the range of boiling points. (See fig. 2.)

After three such distillations further separation became slow, and fractional crystallization was begun on those fractions which gave promise of yielding crystals before they became very viscous. This appeared to be the case only for the fractions in the neighborhood of the boiling point of $n$-octane. The change in the initial freezing point of the cuts with their boiling points is shown in Figure 3. It was found possible to remove material having the properties of $n$-octane from fractions boiling as low as $121^{\circ}$ to $122^{\circ}$ and as high as $127^{\circ}$ to $128^{\circ}$, but below $123^{\circ}$ to $124^{\circ}$ and above $126^{\circ}$ to $127^{\circ}$ the process was slow because of the low concentration of $n$-octane, the low temperature required to freeze the fractions, and the high viscosity of the liquid.

\section{APPARATUS FOR CRYSTALLIZATION}

In designing apparatus for the crystallization, some of the requirements to be met were: (1) Ease in attaining a wide range of low temperatures, (2) ability to cool large quantities rapidly, (3) rapid filtration of viscous material, (4) close approach to equilibrium be-

\footnotetext{
7 Kanolt, B. S. Sci. Paper No. 520, p. 625; 1926.

8 Sce footnote 6, n. 377 .

See Washburn, Bruun, and Hicks, B. S. Jour. of Research, 2, p. 469; 19:9,

10 Described in 13 . S. Jour. of Research, 2, p. 470; 1929.
} 

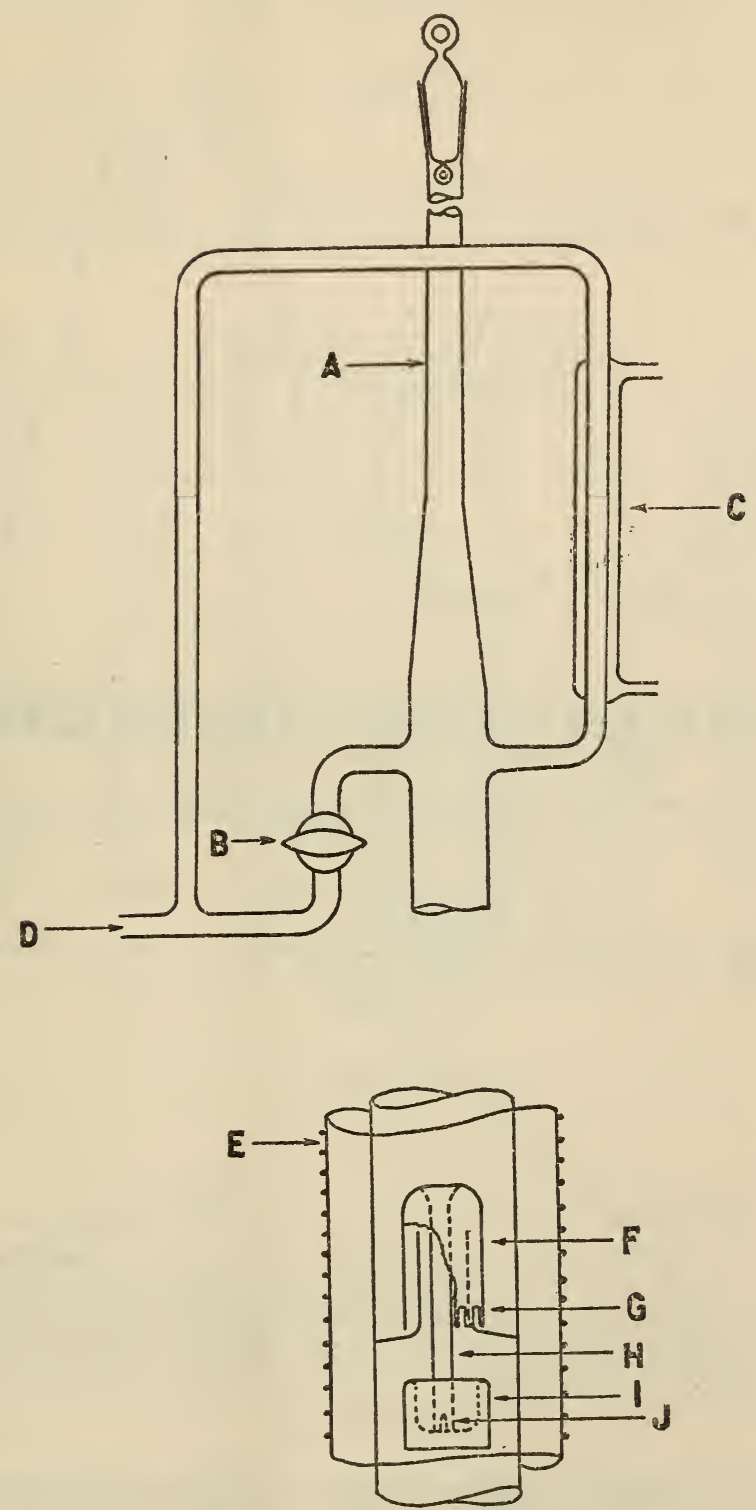

Frgure 1.-Essential parts of glass bubbling-cap stills and reflux heads

$A$, thermometer well; $B$, stopcock for removing variable portions of condensible gas; $C$, condenser for returning remainder of condensible gas to still head; $D$, exit to condensing system; $E$, glass jacket wound with chromel heating wire; $F$, cap under which vapor passes; $G$, slots ground in cap for breaking up vapor stream into small bubbles; $H$, overflow tube returning liquid to plate below; $I$, cup forming liquid seal to prevent passage of vapor up overflow tube; $J$, slots allowing passage of liquid from tube to cup. 


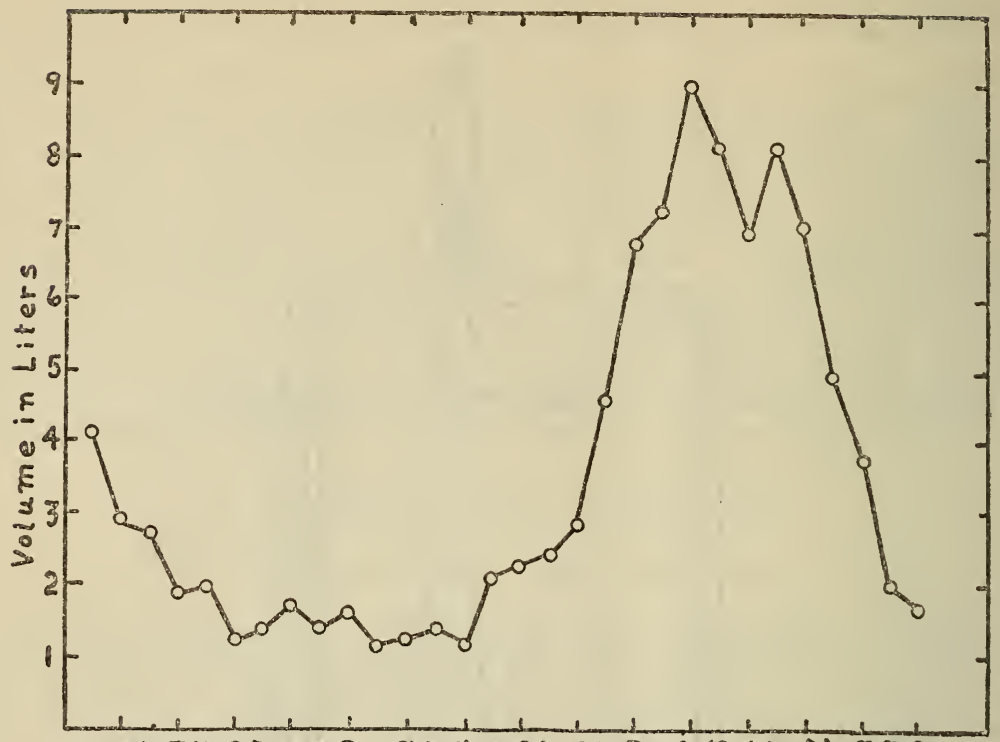

อ lipper Temperdture of Cut in ${ }^{\circ} \mathrm{C}$.

FIGURE 2.-Distribution of volume with boiling point after three distillations in glass stills

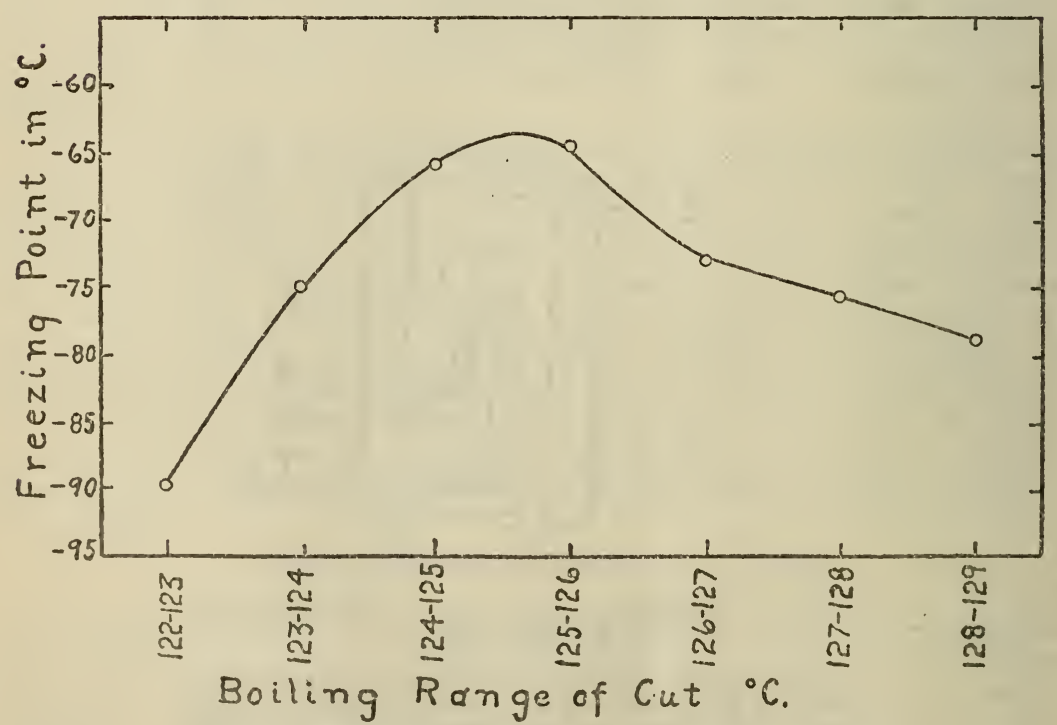

FIGURE 3.-Change in the freezing point with the boiling point of fractions 
tween phases, and (5) as complete separation of the liquid from the crystals as possible. Several methods for accomplishing these results were tried. In all of them the material was frozen to a slush which was not too thick to permit vigorous stirring so that intimate contact between the phases could be maintained in spite of the low thermal conductivity of the material.

The simplest method consisted in cooling the material in a metal cylinder by means of a slush of carbon dioxide in a mixture of chloroform and carbon tetrachloride till a solid phase appeared and
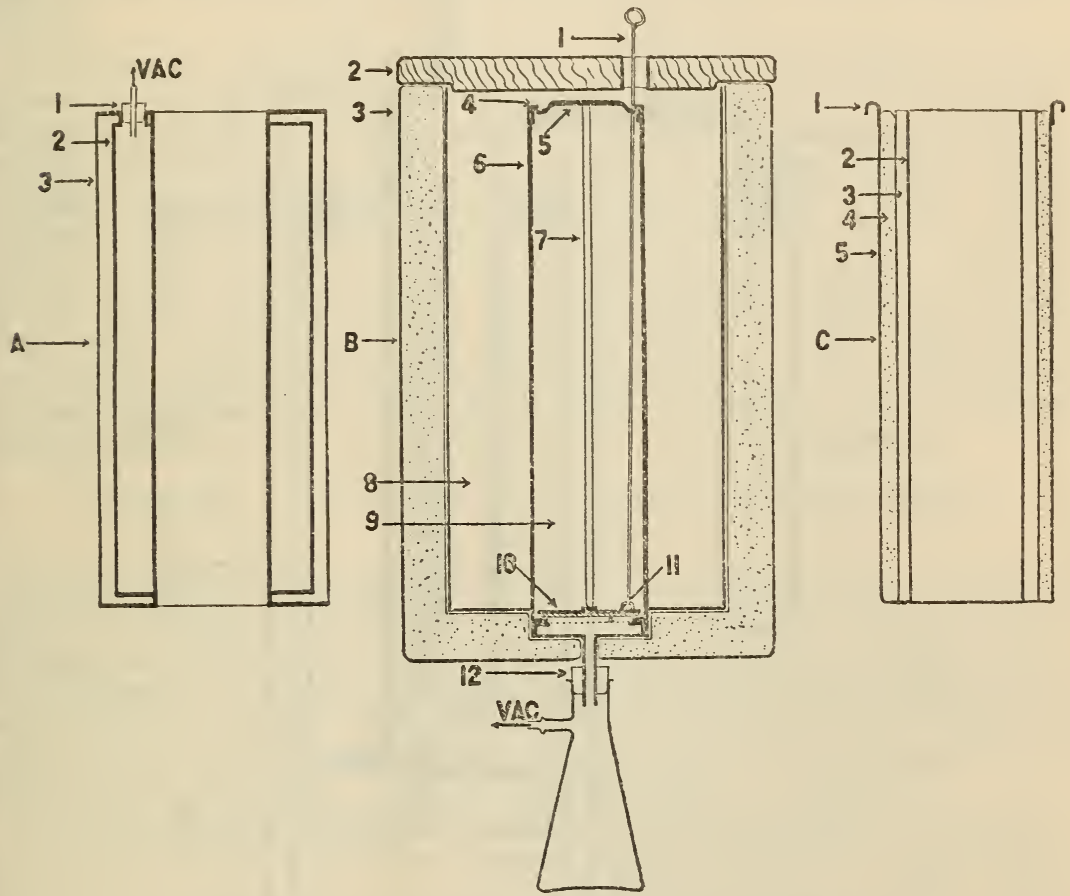

FIGURE 4.-Apparatus used for fractional crystallization

A, (1) opening for filling inner chamber; (2) chamber containing carbon dioxide ice in ether; and (3) air space for thermal insulation between inner and outer baths

$B$, (1) brass rod for withdrawing plate which covers filter surface; (2) wooden cover; (3) felt insulating material (4) brass cleats; (5) phosphor-bronze spring; (6) brass cylinder; (7) rod transmitting pressure from spring to plate; (8) space for freezing mixture; (9) space for mizture to be crystallized; (10) heavy bress disk faced with leather forming liquid-tight seal; (11) copper gauze filter (200 mesh); and (12) rubber stopper.

$C$, (1) handles; (2) tube fitting snugly over $B-6$; (3) space for cooling or warming agent; (4) felt insulation; and (5) sheet metal

drawing off the liquid with a pipette having a wire gauze tip as filter medium. The cylinder was then withdrawn from the slush and allowed to warm, while stirring, until another fraction could be removed, etc.

A somewhat more effective type of apparatus is shown in Figure 4. The material placed in the central tube of $B$ was cooled by carbon dioxide slush in the space surrounding it. In order to reach temperatures somewhat below those attainable by carbon dioxide ice at atmospheric pressure, the drum, $A$, was slipped over the central tube of $B$ after preliminary cooling in the usual way, and the pressure was 
reduced on the mixture of ether and carbon dixoide ice in $A-2$. As an additional method of varying the temperature, $A$ could be replaced by $C$, into the inner annular space of which liquid air could be introduced for further cooling, or a warm liquid if a higher temperature was desired. When the sample had been cooled till a thick

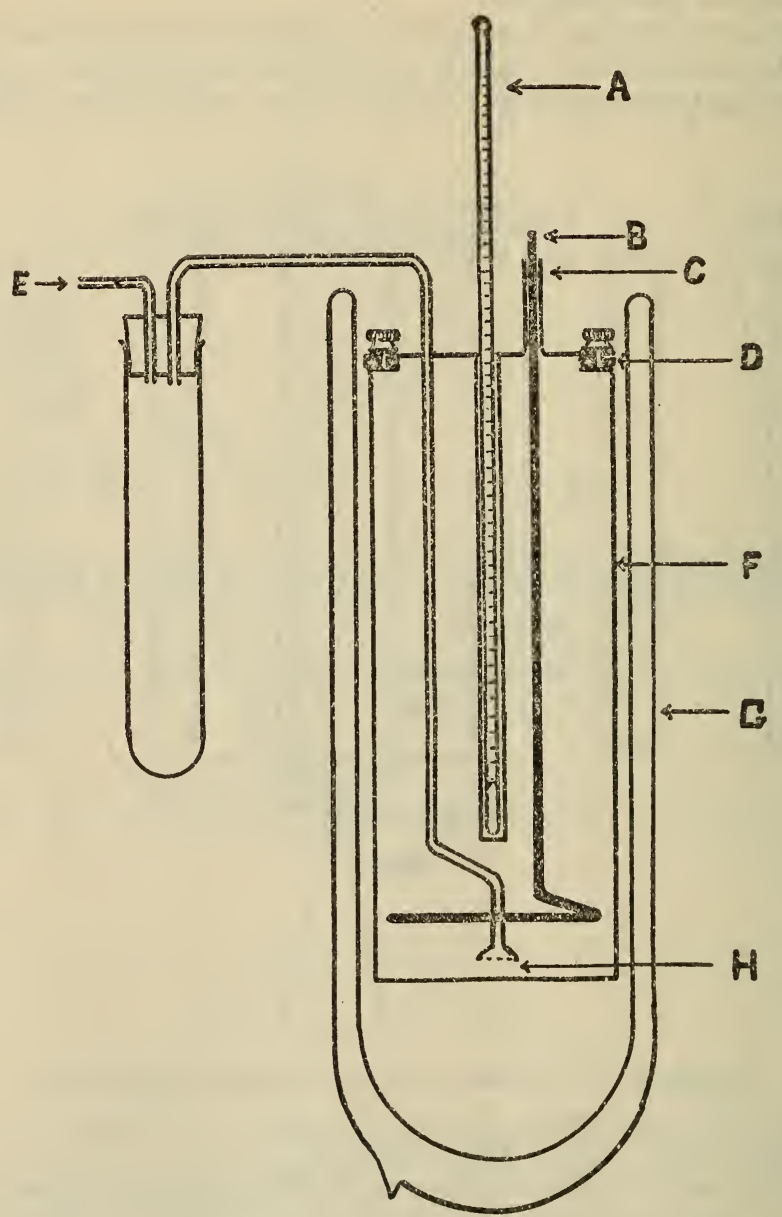

FigdRe 5.-Apparatus for filtration of viscous materials under pressure

$A$, pentane thermometer; $B$, brass rod stirrer; $C$, inlet for compressed gas between stirrer and walls of tube; $D$, leather gasket; $E$, tube to vacuum line; $F$, heavy wall brass cylinder; $A$, Dewar tube; $I I$, filter medium

slush resulted, the plate, $B-10$, was removed and the liquid drawn off through the filter gauze.

The best results were obtained with an apparatus of the type shown in Figure 5. The contents of the cylinder were cooled by immersion first in the carbon dioxide slush and then in a Dewar tube containing a small quantity of liquid air. The liquid was forced 
through the filter by compressed air entering at $C$ and suction applied at $E^{11}$

\section{METHOD OF FRACTIONAL CRYSTALLIZATION}

The fractions of a single distillation which were found to yield octane were each crystallized once separately. This was done because, though a number of fractions could be made to yield octane, some were much richer than others. The resulting fractions were then united for further fractionation, since their indices of refraction and freezing points were approximately the same; and the mother liquors were redistilled or combined on the basis of their refractive indices.

In order to remove the octane as completely as possible, it was necessary to perform a systematic fractionation. Two slightly different procedures were employed, in one of which equilibrium melting was allowed to continue with each lot frozen until the final crystals were sufficiently pure to be considered as product. This method resulted in a large number of liquid fractions of various sizes some of which differed only slightly in refractive index. In the second method, each "freeze" was separated into only two or three fractions, the cuts being made when the refractive index showed the most rapid change with the volume of liquid drawn off. The latter method was found to be the most rapid in practice, and a typical example of the course of this procedure is shown in Figure 6.

\section{METHOD OF INTERLOCKING CRYSTALLIZATION WITH DISTILLATION}

The fractional crystallization divided the material into a series of fractions ranging in refractive index from that of $n$-octane up to values considerably higher than that of the material as obtained from the distillation. The material with high index and low freezing point was redistilled while the fractions with low index, which were too small for further crystallization were added to the appropriate crystallization fractions from the next lot of new material.

The chart shown in Figure 7 outlines the actual course of the work. It is to be read from the top down. Thus, the first row of circles represents the cuts from the third distillation in glass stills. Only a part of the $124^{\circ}$ to $125^{\circ}$ fraction was crystallized and the crystalline portion was saved until more material was obtained from the fourth distillation before further fractionation. This is indicated by the broken line leading to the right from the small square under the $124^{\circ}$ to $125^{\circ}$ iraction.

The second row of large circles represents the fractions of the fourth distillation. Four fractions of this disillation were crystallized, and the crystalline fractions united for the systematic fractional crystallization represented by the large square, $A$, at the right. Figure 6 is typical of the process which this square represents. This crystallization produced 4 liters of product represented by the square, $B_{1}$, (fig. 7), and a series of residual fractions as explained before which are represented by the square, $C_{1}$.

Of the fifth distillation six cuts were fractionated. The residual fractions, $C_{1}$, were worked into this fractionation for further treat-

11 This apparatus is quite similar to that used by Kanolt in the determination of the viscosity of liquids. See R. S. Sci. Paper No. 520, p. 628; 1926. 
ment. Two liters of product was obtained; $C_{2}$ represents the resi-d ual fractions too small for further work; and the circle, $D_{2}$, represents material of such low octane content that fractionation was impractical. The broken line leading back from $D_{2}$ toward the distillation indicates that the material was redistilled, and added to the corresponding fractions of the sixth distillation. The remainder of the chart is to be interpreted in the same way.

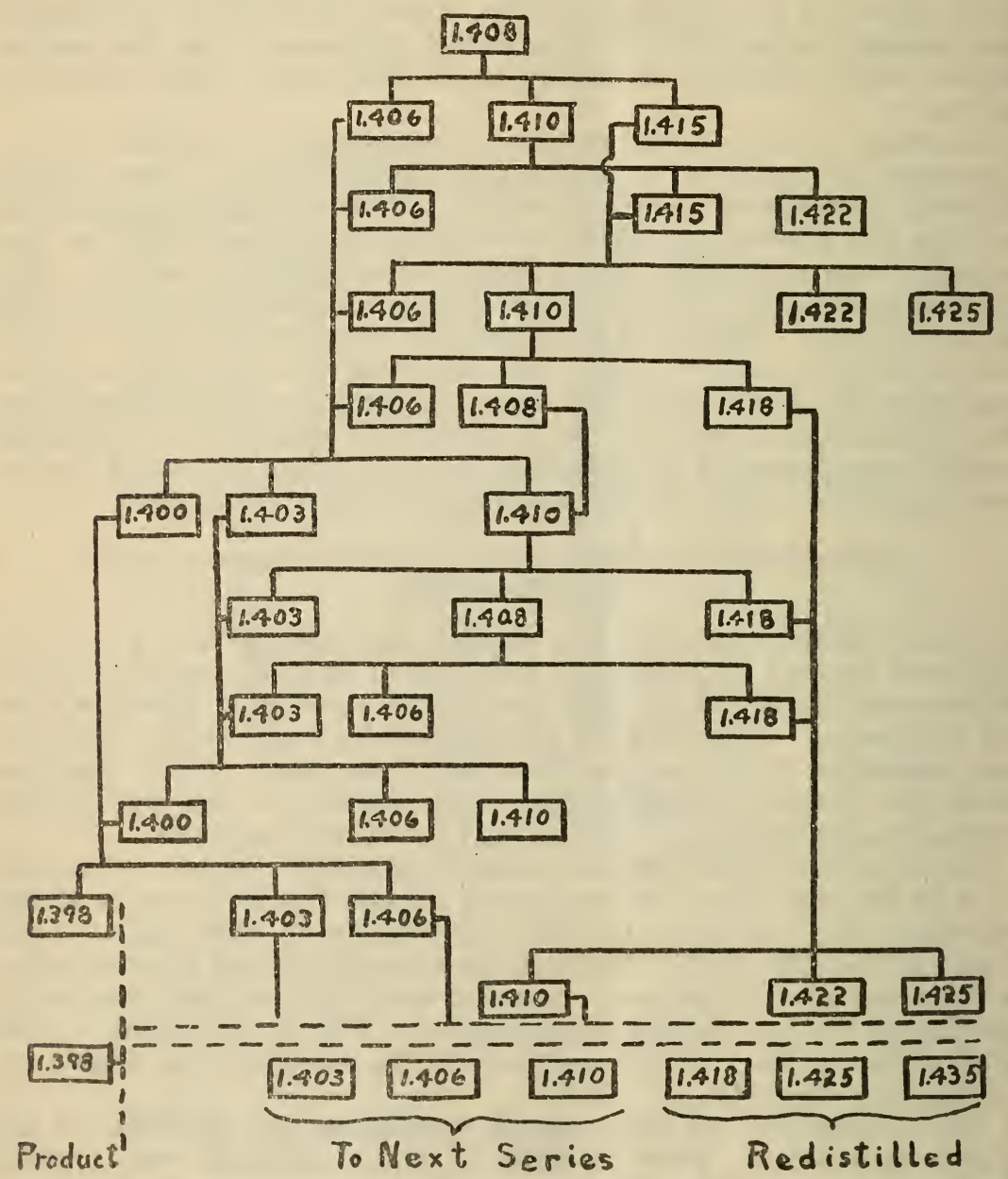

Figure 6.-A typical fractional crystallization

\section{PROPERTIES OF THE PRODUCT}

After 11 distillations in glass stills interspersed with five fractional crystallizations, 12.75 liters of approximately pure $n$-octane was collected. In Table 1 the physical properties of the product are compared with those of an especially purified synthetic sample. ${ }^{12}$ The properties were measured with the same apparatus and as nearly

12 Preparod by 13. J, Mair, research associate, Nationul Bureau of Standards. 
Distillation

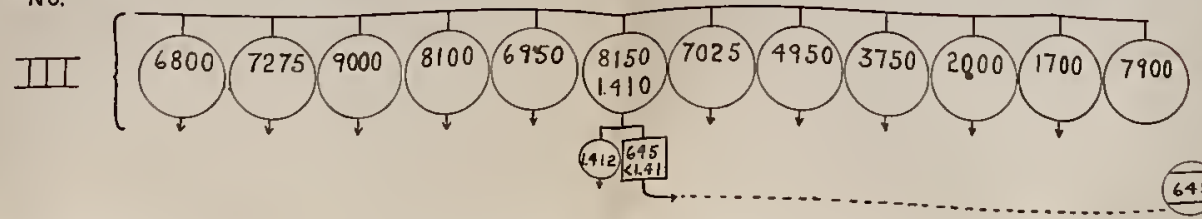

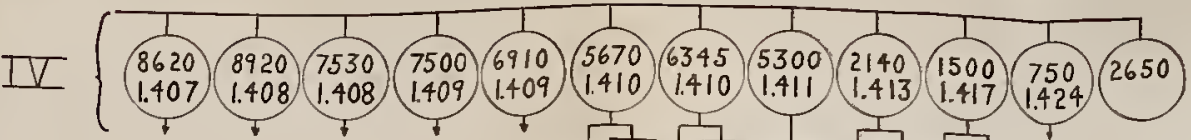

(1.400)

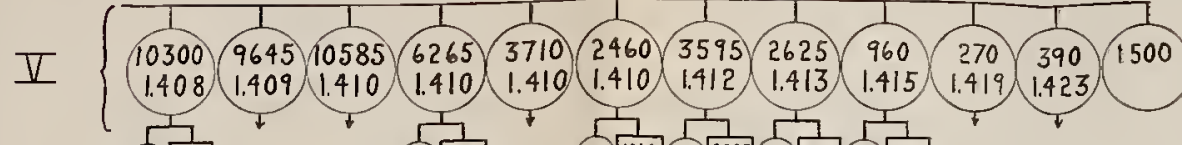

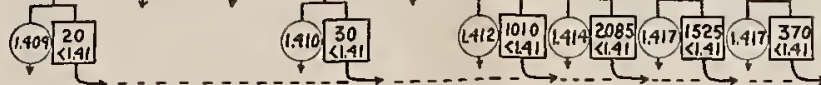

. . . . . .

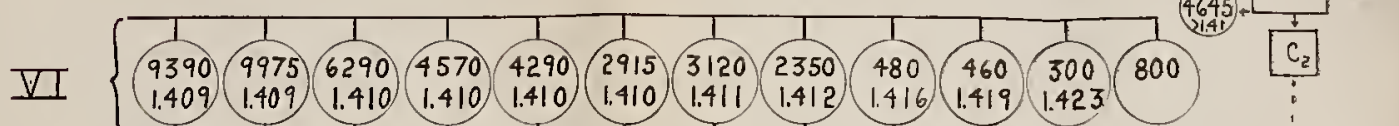
(1.409) 1.409 ?

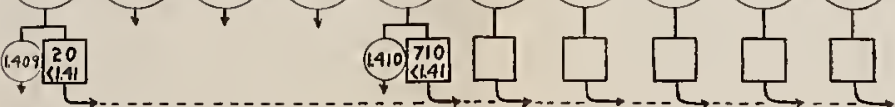

A. $\rightarrow \frac{4000}{B !}$$$
\text { 西 }
$$$$
\text { III }
$$

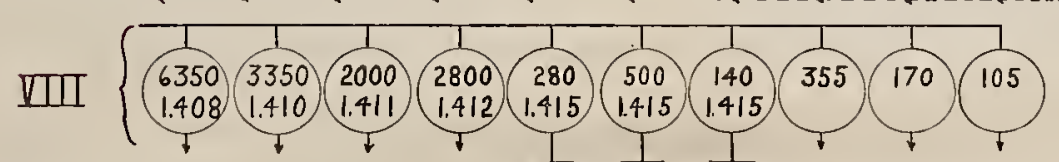$$
\text { Temp. }
$$$$
120^{\circ}
$$$$
\sum_{\frac{12}{1} 5^{\circ}}
$$$$
\text { IX } 3\left(\begin{array}{l}
4900 \\
3750
\end{array}\right.
$$$$
\square_{-}
$$$$
X\left\{\left(\begin{array}{lll}
7620 \\
1
\end{array}\right.\right.
$$

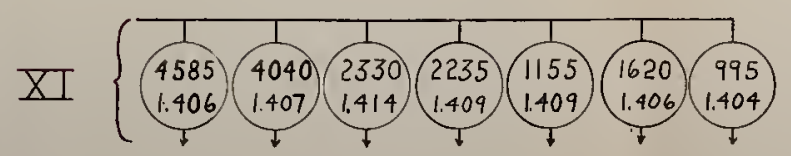
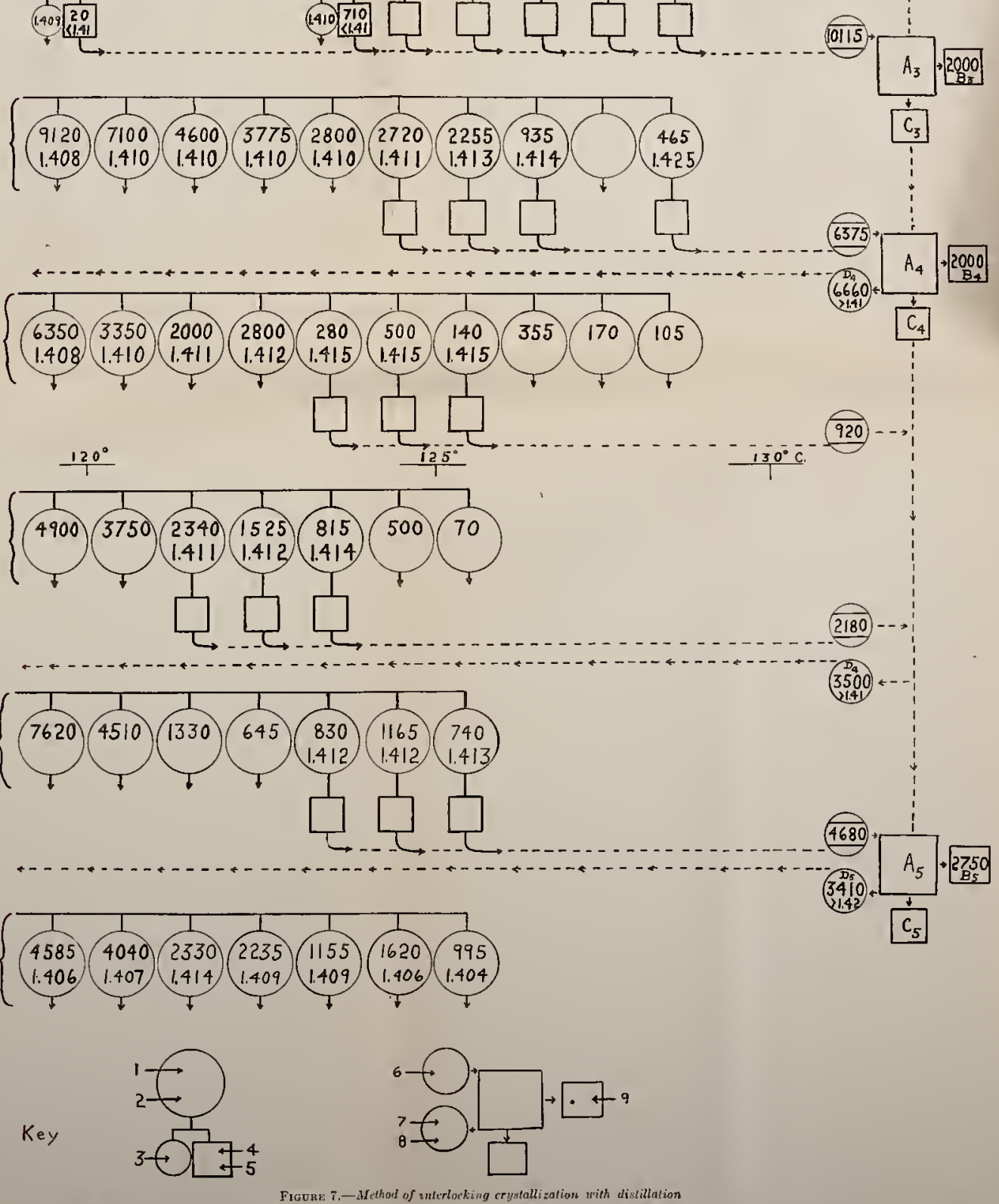
as possible in the same way in each case, and for purposes of comparison should be reliable to the number of significant figures given. No attempt was made to reach the ultimate purity obtainable on all the material, but rather to obtain the maximum quantity of material of approximate purity. As a result, the various lots differ somewhat in purity. In two instances, however, samples of much higher purity were produced, one by physical separation and the other by chemical destruction of the impurities. The first of these, Lot VII, was collected in the process of one of the regular fractionations by allowing the equilibrium melting to continue longer than usual. The second one, Lot VIII, was obtained by treating $200 \mathrm{ml}$ of Lot II with $300 \mathrm{ml}$ of chlorosulphonic acid and stirring continuously for seven days. This treatment has been shown to destroy normal paraffin hydrocarbons more slowly than the other classes so that almost pure normal paraffins can be obtained from mixtures in which the other classes are present as minor constituents. ${ }^{13}$

TABLE 1.-Comparison of properties of n-octane obtaincd from petroleum with the properties of synthetic n-octane

\begin{tabular}{|c|c|c|c|c|c|c|}
\hline Material & Volume & $n_{\mathrm{D}}^{20}$ & $\begin{array}{c}\text { Compara- } \\
\text { tive boil- } \\
\text { ing point } \\
760 \mathrm{mma} \\
\mathrm{Hg}\end{array}$ & $\begin{array}{c}\text { Initial } \\
\text { freezing } \\
\text { point }\end{array}$ & $\begin{array}{c}\text { Mole per- } \\
\text { centage } \\
n \text {-octane }\end{array}$ & $\begin{array}{c}\text { Molecular } \\
\text { weight } 1\end{array}$ \\
\hline $\begin{array}{l}\text { Synthetic } n \text {-octane. } \\
\text { Lot I } \\
\text { Lot II } \\
\text { Lot III } \\
\text { Lot IV }\end{array}$ & $\begin{array}{l}2,000 \\
2,000 \\
2,750 \\
2,000\end{array}$ & $\begin{array}{l}\text { 1. } 3970 \\
\text { 1. } 3985 \\
1.3990 \\
\text { 1. } 3980 \\
1.3985\end{array}$ & $\begin{array}{l}{ }^{\circ} \mathrm{C} . \\
125.7 \\
125.4 \\
125.3 \\
125.4 \\
125.4\end{array}$ & $\begin{array}{l}{ }^{\circ} \mathrm{C} . \\
-56.9 \\
-58.0 \\
-58.0 \\
-58.2 \\
-57.7\end{array}$ & $\begin{array}{r}100 \\
94.6 \\
94.6 \\
93.7 \\
96.0\end{array}$ & $\begin{array}{l}(114.1) \\
113.2 \pm 0.3\end{array}$ \\
\hline $\begin{array}{l}\text { Lot V VI } \\
\text { Lot VI VII } \\
\text { Lot VIII }\end{array}$ & $\begin{array}{r}2,000 \\
2,000 \\
100 \\
77\end{array}$ & $\begin{array}{l}\text { 1. } 3975 \\
\text { 1. } 3975 \\
\text { 1. } 3970 \\
1.3970\end{array}$ & $\begin{array}{l}125.5 \\
125.5 \\
125.5 \\
125.4\end{array}$ & $\begin{array}{l}-57.6 \\
-57.7 \\
-57.2 \\
-57.1\end{array}$ & $\begin{array}{l}96.5 \\
96.0 \\
98.5 \\
99.1\end{array}$ & $113.9 \pm 0.3$ \\
\hline
\end{tabular}

1 Molecular weight determinations made by M. M. Hicks-Bruun, National Bureau of Standards.

The mole percentage of $n$-octane in each sample was calculated from the difference in the initial freezing point of the sample and that of the synthetic material. The heat of fusion was taken to be 40.3 cal./g. ${ }^{14}$

From the maximum and minimum values of the molecular weight of Lot II and the mole percentage of $n$-octane calculated from the freezing point, the average molecular weight of the contaminating material is shown to lie between 90 and 103 .

The cooling curves from which the freezing points were determined are reproduced in Figure 8 because they offer considerable evidence regarding the purity of the samples. Figure 9 is a photograph of the long, prismatic crystals obtained by slow cooling.

After completing the above tests Lots I to VI, inclusive, were distilled through a 30 -foot column packed with jack chain. Of the material, 93.3 per cent distilled between $125^{\circ}$ and $126^{\circ}$ C.; 4.2 per cent distilled below $125^{\circ} \mathrm{C}$.; and 2.5 per cent distilled above $126^{\circ} \mathrm{C}$.

${ }_{13}$ Shepard and Henne, Ind. Eng. Chem., 22, p. 356; 1930.

if Parks and Todd, Ind. Eng. Chem., 21, p. 1235; 1929.

$36798^{\circ}-31-3$ 


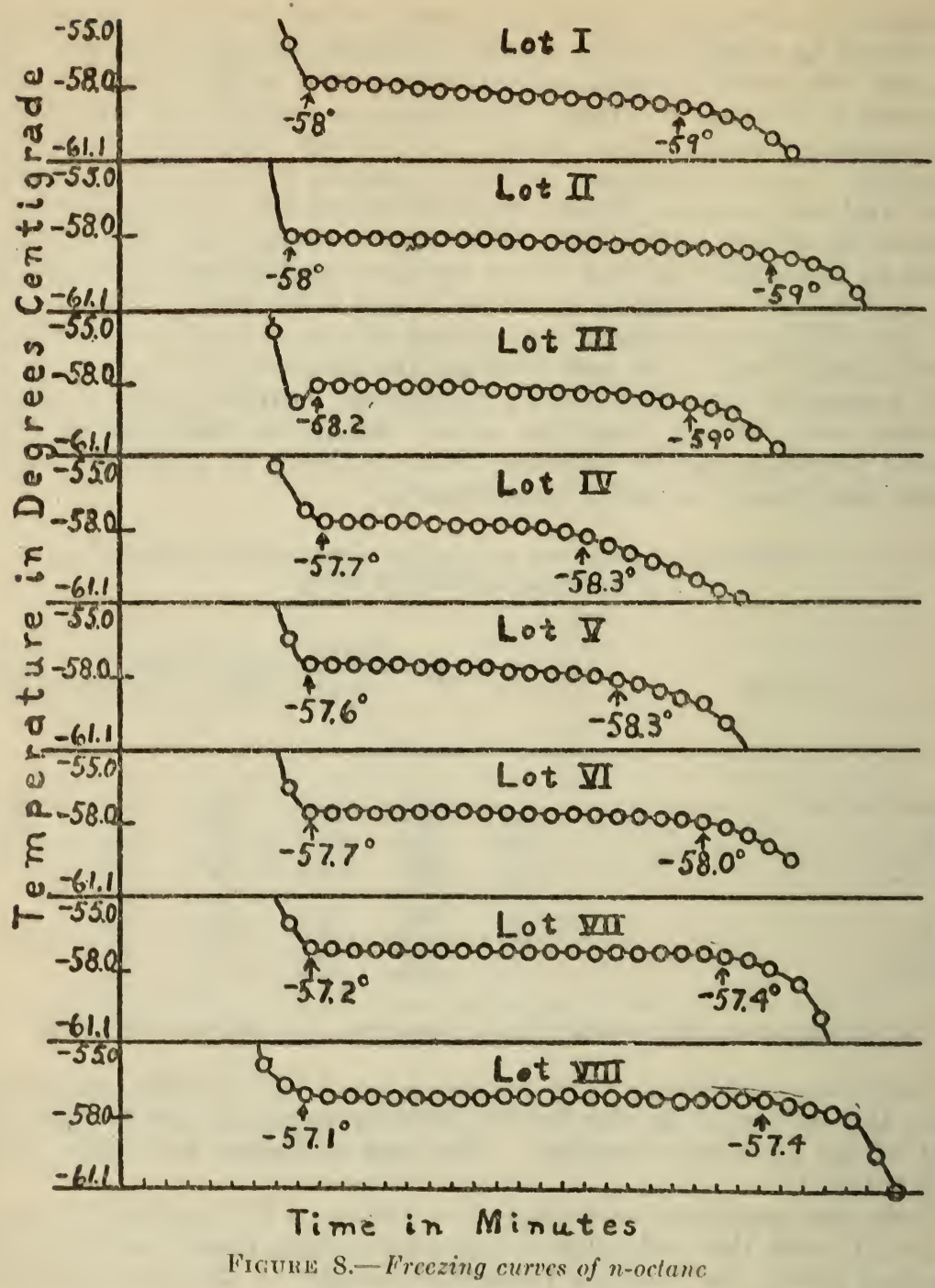

IV. OCTANE CONTENT OF THE CRUDE OIL

After making reasonable allowance for losses incurred in the various operations it is safe to conclude that the $n$-octane content of the crude oil was not less than 1.0 per cent.

Washington, December 26, 1930. 


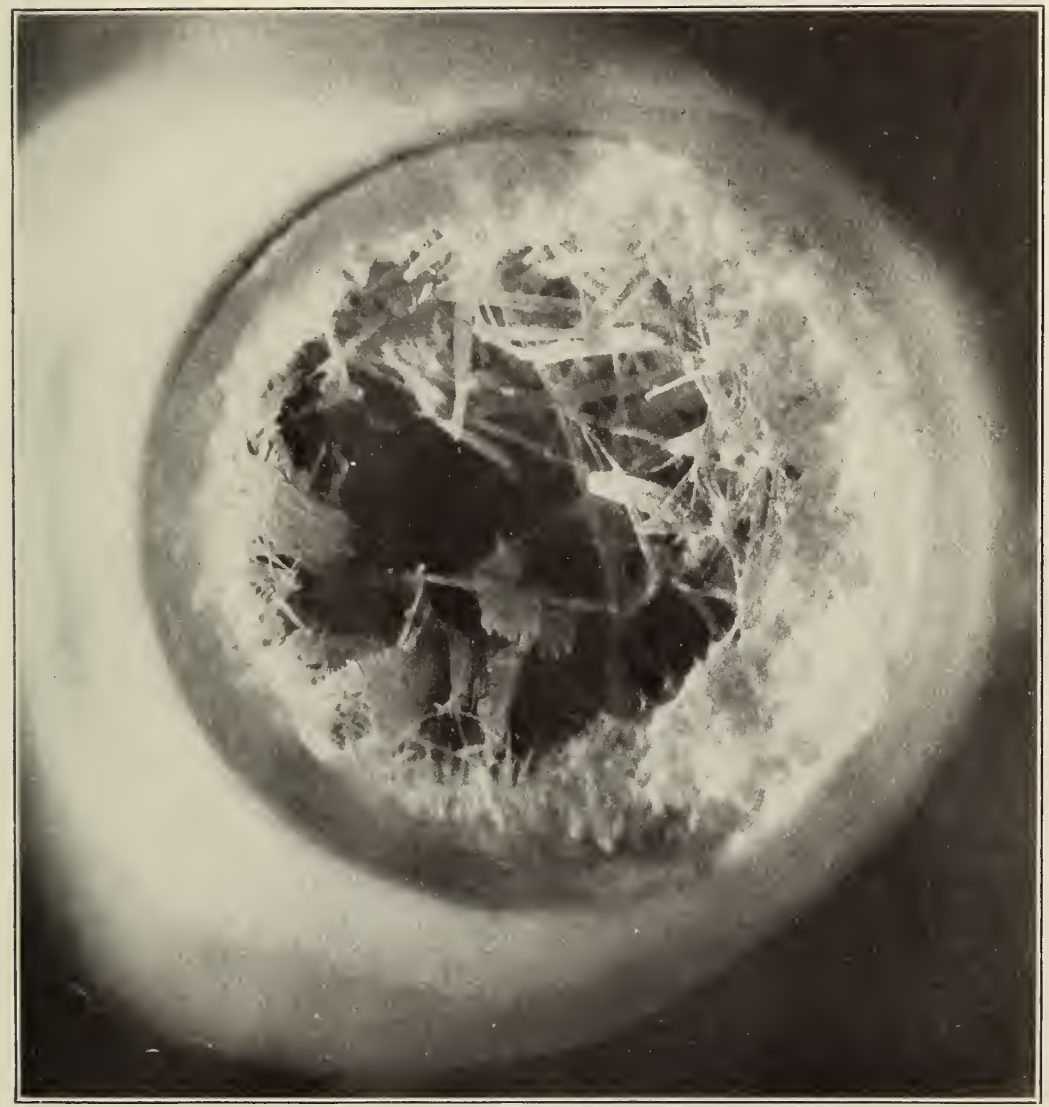

FIGURE 9.-Photograph of n-octane crystals. $\quad \times 4$ 